\title{
Penerapan Aplikasi Augmented Reality sebagai Media Pembelajaran Digital di Taman Kanak-Kanak
}

\author{
${ }^{1}$ Vihi Atina, ${ }^{1}$ Nurchim*, ${ }^{2}$ Yommy Adhiwira Yudha \\ ${ }^{1}$ Fakultas Ilmu Komputer, Universitas Duta Bangsa, Surakarta, Indonesia \\ ${ }^{2}$ Program D3-Manajemen Informatika, Universitas Duta Bangsa, Surakarta, Indonesia \\ *Corresponding Author \\ Jl. Bhayangkara No 55, Surakarta, Jawa Tengah Indonesia \\ Telp. (+62271) 719552, Fax (+62271) 713758 \\ E-mail: nurchim@udb.ac.id \\ Received: Revised: Accepted: Published: \\ 28 April 2020 1 December 2020 15 December 202025 December 2020
}

\begin{abstract}
Abstrak
Penerapan Teknologi Informasi dan Komunikasi (TIK) perlu ditingkatkan guna mendorong keberhasilan transformasi digital dalam dunia pendidikan. Kegiatan ini bertujuan menerapkan aplikasi augmented reality sebagai media pembelajaran digital di Taman Kanak-Kanak (TK) khususnya di TK Kemala Bhayangkari No 72 Wonogiri dengan materi belajar tentang profesi. Tahapan dalam menerapkan aplikasi ini meliputi (1) pengamatan masalah, (2) penerapan teknologi, (3) pelatihan mitra dan (4) pendampingan mitra. Hasil penerapan aplikasi augmented reality yakni dapat meningkatkan kompetensi guru dalam menggunakan media digital dan menyediakan sarana prasarana pembelajaran digital. Selain itu, proses kegiatan belajar mengajar dengan memanfaatkan media digital menjadi lebih menarik dan interaktif.
\end{abstract}

Kata kunci: pembelajaran; digital; augmented reality; mobile; aplikasi

\begin{abstract}
The implementation of Information and Communication Technology (ICT) needs to be improved to encourage the success of digital transformation in the world of education. This activity aims to apply the augmented reality application as a digital learning media in kindergarten especially in TK Kemala Bhayangkari No. 72 Wonogiri with learning material about the profession. The stages in implementing this application include (1) observation of the problem, (2) application of technology, (3) partner training, and (4) partner assistance. The results of implementing the augmented reality application are that it can increase teacher competence in using digital media and provide digital learning infrastructure. In addition, the process of teaching and learning activities using digital media is becoming more interesting and interactive.
\end{abstract}

Keywords: learning; digital; augmented reality; mobile; application 


\section{PENDAHULUAN}

Taman Kanak-Kanak (TK) adalah bentuk pendidikan formal anak usia dini yang diatur pada Undang-Undang Nomor 20 Tahun 2003 pasal 28 ayat 3. Program pendidikan TK diperuntukan bagi anak usia 4-6 tahun yang bertujuan meningkatkan pertumbuhan dan perkembangan anak melalui pemberian rangsangan, agar anak memiliki kesiapan melanjutkan ke pendidikan dasar (Delfita, 2012). Selain itu, pendidikan TK juga digunakan untuk mengembangkan potensi fisik anak maupun psikis yang terdiri dari aspek sosial, moral, emosional, kognitif, kemandirian, motorik, bahasa, dan seni (Gusnita, dkk, 2019). Metode pembelajaran di TK lebih cenderung dilakukan dengan cara bermain, karyawisata, bercakap-cakap, bercerita, demonstrasi, proyek dan pemberian tugas sehingga menarik minat belajar anak (Roza, 2012). Pembelajaran profesi adalah salah satu materi pembelajaran yang perlu sejak dini dikenalkan ke anak, supaya anak memahami peranan mereka di masyarakat (Hanafri, dkk, 2017).

Pembelajaran profesi atau pekerjaan ini juga dilakukan di TK Kemala Bhayangkari No 72 yang berlokasi di Kabupaten Wonogiri. TK Kemala Bhayangkari No 72 didirikan dibawah Yayasan Kemala Bhayangkari cabang Wonogiri memiliki 4 kelas meliputi TK A1, TK A2, TK B1 dan TK B2. Sedangkan pengelola TK Kemala Bhayangkari No 72 terdiri dari Kepala Sekolah dan 4 orang Guru. Sekarang, proses pembelajaran di TK Kemala Bhayangkari mengacu Kurikulum Tingkat Satuan Pendidikan (KTSP) Pendidikan Anak Usia Dini dengan materi profesi yang disampaikan ke anak yaitu pembelajaran profesi Polisi dan Sopir.

Proses pembelajaran profesi Polisi dan Sopir di TK Kemala Bhayangkari No 72 selama ini dilakukan dengan cara mengenalkan anak-anak dengan rambu-rambu lalu lintas. Media pembelajaran yang digunakan guru berupa macam-macam gambar yang dicetak dalam bentuk spanduk dan poster. Selama ini, media pembelajaran tersebut dipasang di lingkungan TK dengan tujuan agar anak dapat mudah melihat atau mengenal seperti yang ditampilkan pada Gambar 1. Namun, bahan pembelajaran ini mudah sobek terkena angin dan cetakannya menjadi tidak jelas karena sering terkena air hujan sebagaimana ditunjukan pada Gambar 2. Akibatnya, pihak TK meski sering mengganti jika media tersebut sudah tidak layak pakai.

Selain rambu-rambu lalu lintas, anak-anak juga dikenal dengan Alat Pemberi Isyarat Lalu Lintas (APILL). Pembelajaran APILL di TK Kemala Bhayangkari No 72 dilakukan dengan mengundang petugas Kepolisian Satuan Lalu Lintas (Satlantas) Wonogiri. Polisi Satlantas diminta untuk menjelaskan sekaligus memperagakan beberapa APILL secara langsung ke anakanak. Pembelajaran ini tidak dapat dilakukan setiap hari, karena harus menyesuaikan dengan jadwal petugas Polisi Satlantas. Dengan demikian, perlu dilakukan pengembangan inovasi media pembelajaran untuk memecahkan permasalahan dalam proses pembelajaran ramburambu lalu lintas dan APILL yang terjadi saat ini.

Alternatif yang dapat dikembangkan yakni media pembelajaran berbasis teknologi informasi khususnya pemanfaatan multimedia dan Augmented Reality (AR). Multimedia dikenal lebih interaktif untuk meningkatkan kemampuan anak dalam mengenali unsur gambar dan warna (Handayani, 2018). Ditambah adanya AR dapat mempermudah guru mempersiapkan materi pembelajaran serta pengajaran ke anak menjadi menarik dan atraktif (Lee et al., 2019). Kegiatan pengabdian masyarakat ini bertujuan untuk implementasi aplikasi AR sebagai media pembelajaran digital di TK Bhayangkari No 72 Wonogiri. 
Indonesian Journal of Community Services

Volume 2, No. 2, November 2020

http://jurnal.unissula.ac.id/index.php/ijocs

DOI: http://dx.doi.org/10.30659/ijocs.2.2.172-180

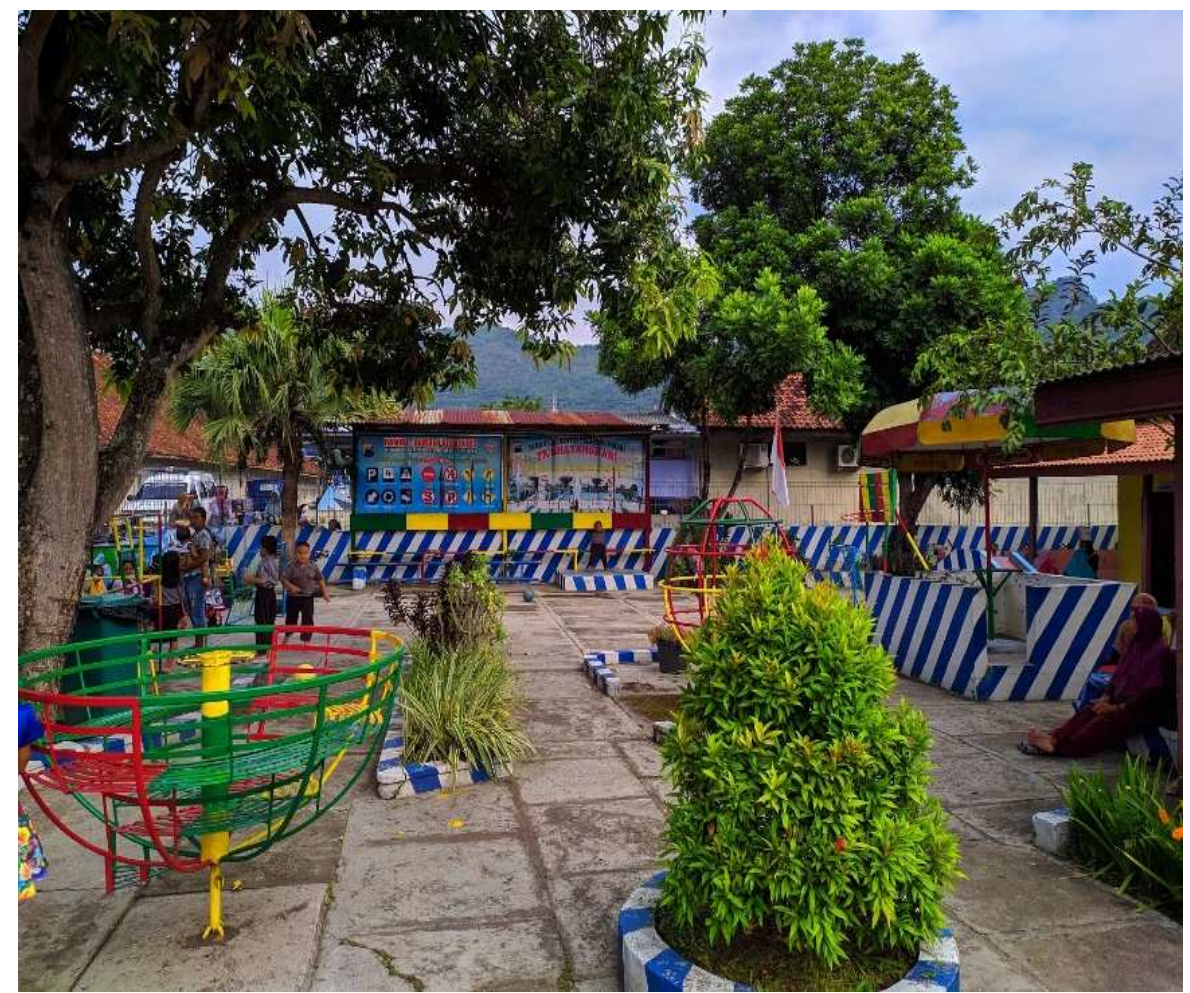

Gambar 1. Lingkungan TK Kemala Bhayangkari No 72 Wonogiri

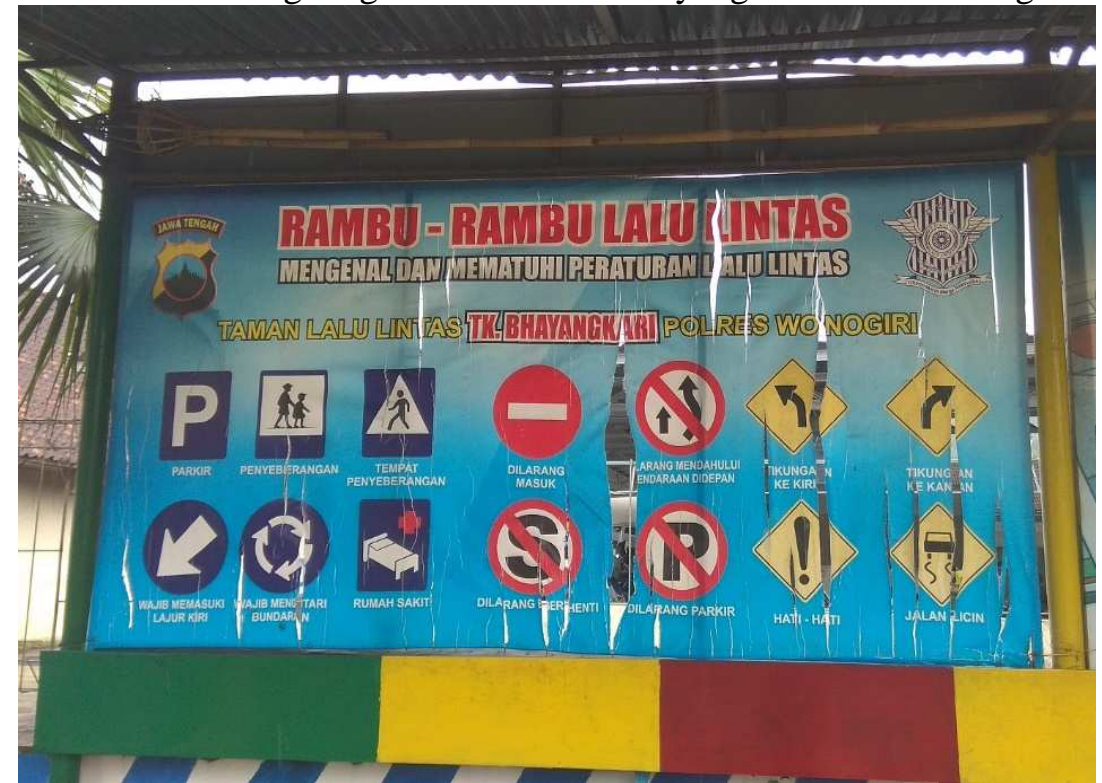

(a) Spanduk media pembelajaran sudah sobek 


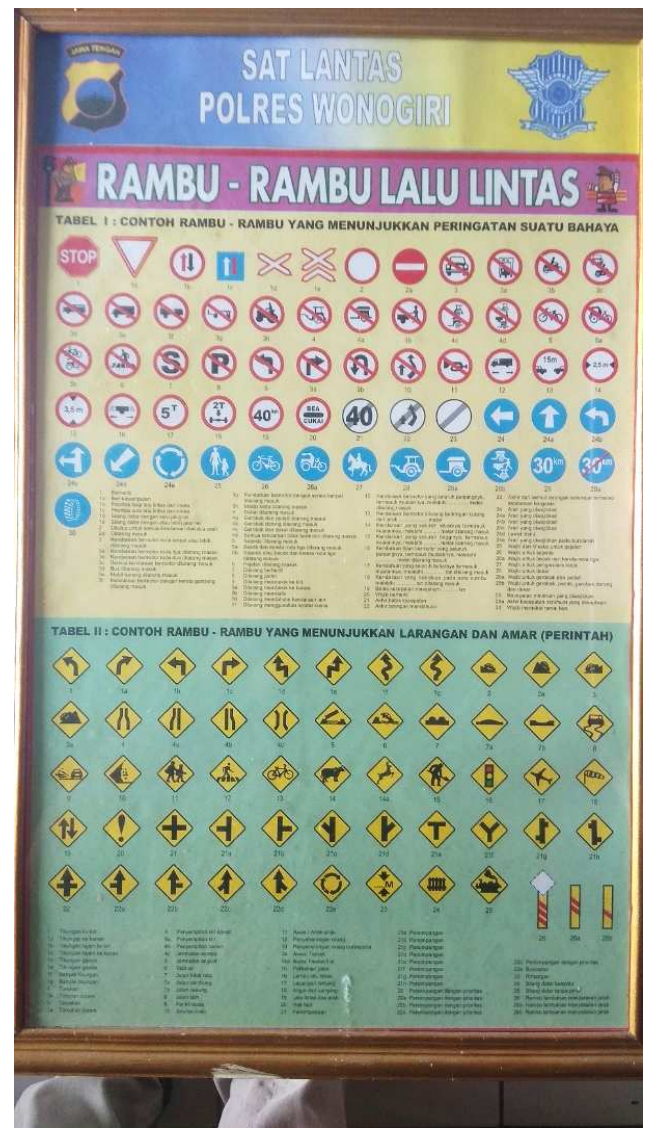

(b) Poster media pembelajaran warnanya mulai pudar

Gambar 2. Kondisi terkini media pembelajaran di TK Kemala Bhayangkari No 72 Wonogiri

Aplikasi AR banyak digunakan sebagai media pembelajaran, yang memiliki fitur dapat merepresentasikan obyek di lingkungan nyata secara virtual (Wahyuni dkk., 2020). Melalui konten digital multimedia yang ditawarkan oleh aplikasi AR, mampu meningkatkan minat membaca anak (Danaei et al., 2020). Bahkan, pemanfaatan aplikasi AR dapat menarik perhatian anak-anak ke materi pembelajaran sehingga mendorong untuk menerapkan apa yang telah dipelajari (Oranç \& Küntay, 2019). Konsep pembelajaran dengan aplikasi AR menghadirkan model pembelajaran baru dan berpeluang mengisi gap dibidang teknologi pendidikan (Yilmaz, 2016).

\section{METODE}

Kegiatan pengabdian masyarakat dilaksanakan di TK Kemala Bhayangkari No 72 yang beralamatkan Jl. Kartini No. 45 Giritirto Kabupaten Wonogiri. Pelaksanan kegiatan pengabdian kepada masyarakat ini mengunakan pendekatan 4P yang terbagi menjadi empat tahapan sebagaimana ditunjukkan pada Gambar 3. Pertama, tahapan pengamatan yang bertujuan untuk mengindetifikasi permasalahan yang dihadapi oleh mitra khususnya dalam segi media pembelajaran serta mendefinisikan solusi yang dibutuhkan berdasarkan sumber daya yang dimiliki mitra sehingga solusinya tepat sasaran. Selanjutnya, tahapan penerapan menggunakan pendekatan User Centered Design (UCD) selain tepat sasaran juga tepat sesuai dengan kebutuhan mitra. Terakhir, pendekatan problem solving digunakan pada tahapan pelatihan dan 
pendampingan mitra sehingga apabila timbul permasalahan dalam proses penerapan teknologi langsung dapat diselesaikan.

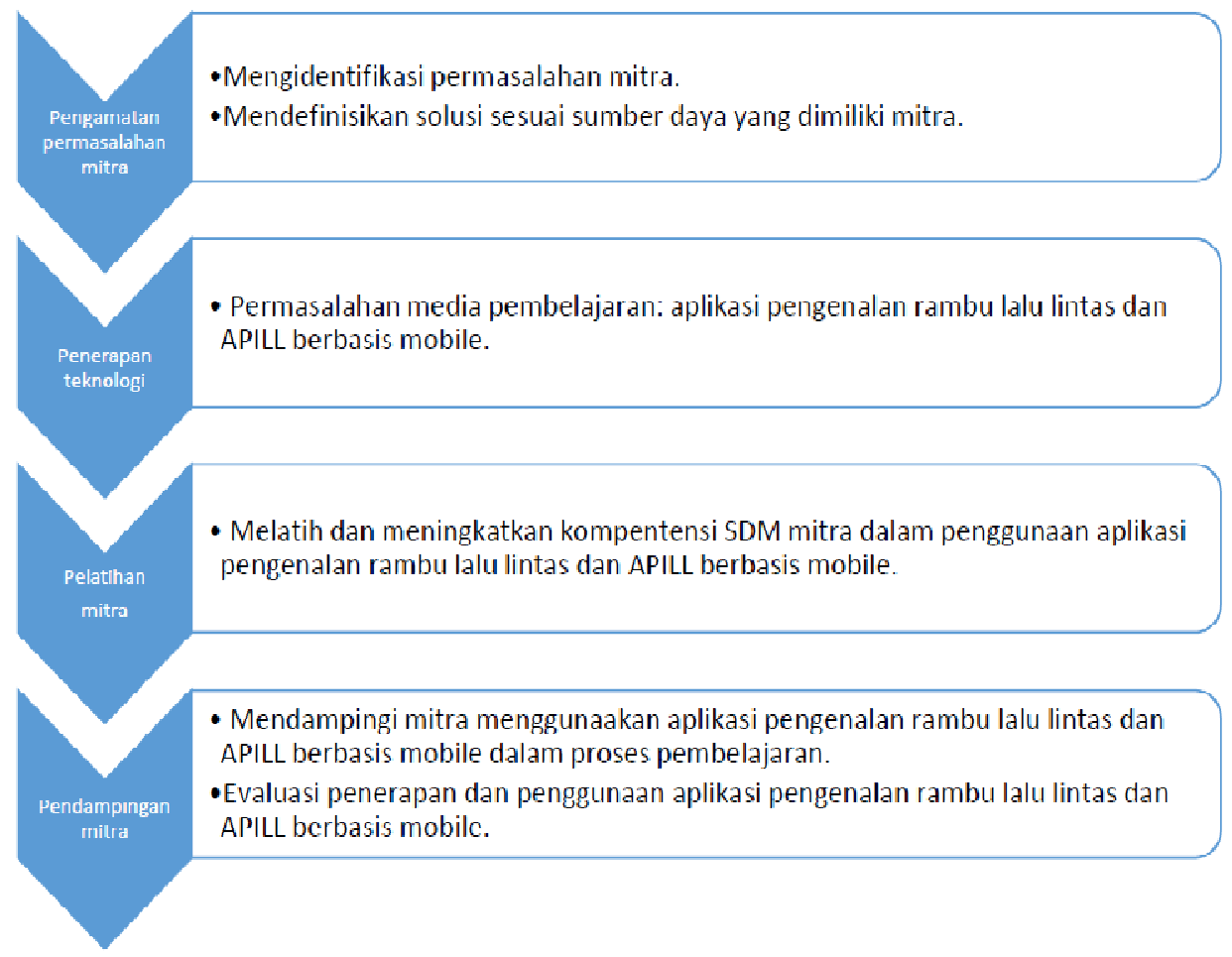

Gambar 3. Tahapan penerapan aplikasi AR sebagai media pembelajaran digital.

\section{HASIL DAN PEMBAHASAN \\ Pengamatan permasalahan mitra}

Berdasarkan hasil observasi di TK Kemala Bhayangkari No 72, bahwa diidentifikasi permasalahan yang timbul di TK tersebut adalah penyediaan media pembelajaran pengenalan profesi khususnya profesi Polisi. Oleh karena itu, dibutuhkan segera inovasi media pembelajaran yang bersifat mudah digunakan, mudah dipahami anak didik dan dapat digunakan kembali. Berikut gambaran solusi yang ditawarkan atas permasalahan tersebut, yang ditunjukkan pada Tabel 1. Pemilihan solusi ini, tidak terlepas dari sumber daya manusia serta sarana prasarana yang dimiliki TK Kemala Bhayangkari No 72. Saat ini, dukungan sarana prasaran di TK Kemala Bhayangkari bahwa sudah terdapat sebuah notebook dan proyektor yang digunakan dalam proses pembelajaran.

Tabel 1. Solusi yang ditawarkan

\begin{tabular}{cccc}
\hline PERMASALAHAN & \multicolumn{2}{c}{$\begin{array}{c}\text { SOLUSI YANG } \\
\text { DITAWARKAN }\end{array}$} & \multicolumn{2}{c}{ TAHAPAN IMPLEMENTASI } \\
\hline Media Pembelajaran & Implementasi aplikasi & 1. & $\begin{array}{l}\text { Melatih guru tentang cara penggunaan } \\
\text { aplikasi pengenalan AR berbasis } \\
\text { Pengenalan Profesi: } \\
\text { Polisi dan Sopir }\end{array}$ \\
& $\begin{array}{l}\text { pengenalan rambu lalu } \\
\text { lintas dan APILL berbasis } \\
\text { mobile }\end{array}$ & 2. $\begin{array}{l}\text { Mendampingi guru dalam proses } \\
\text { pengajaran menggunakan aplikasi AR } \\
\text { berbasis mobile. }\end{array}$ \\
& &
\end{tabular}

Penerapan teknologi

176 || Indonesian Journal of Community Services 
Implemetasi teknologi dilakukan dalam bentuk integrasi proses pembelajaran profesi dengan aplikasi pengenalan rambu lalu lintas dan APILL berbasis mobile. Aplikasi pengenalan rambu lalu lintas dan APILL berbasis mobile ini berisi materi gambar-gambar rambu lalu lintas dan APILL yang dikemas dengan memanfaatkan multimedia dan AR. Jadi ke depan guru dapat menyampaikan materi pengenalan profesi polisi dan sopir, cukup dengan menghubungkan smartphone yang sudah terinstall aplikasi AR berbasis mobile dengan notebook dan ditampilkan melalui proyektor. Penerapan teknologi informasi dan komunikasi ini merupakan kunci sukses dalam melakukan transformasi digital (Nurchim \& Nofikasari, 2018). Gambaran aplikasi tersebut ditampilkan pada Gambar 4.

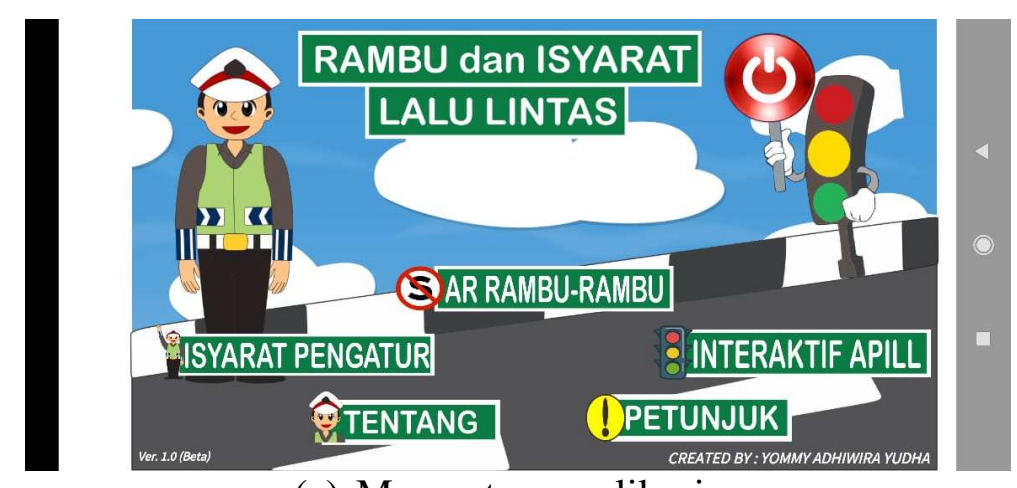

(a) Menu utama aplikasi

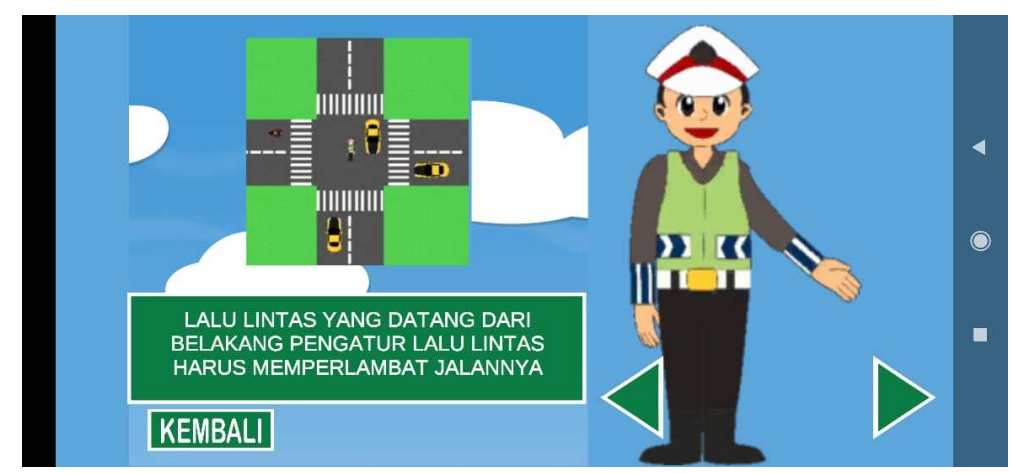

(b) Multimedia interaktif materi isyarat pengaturan lalu lintas

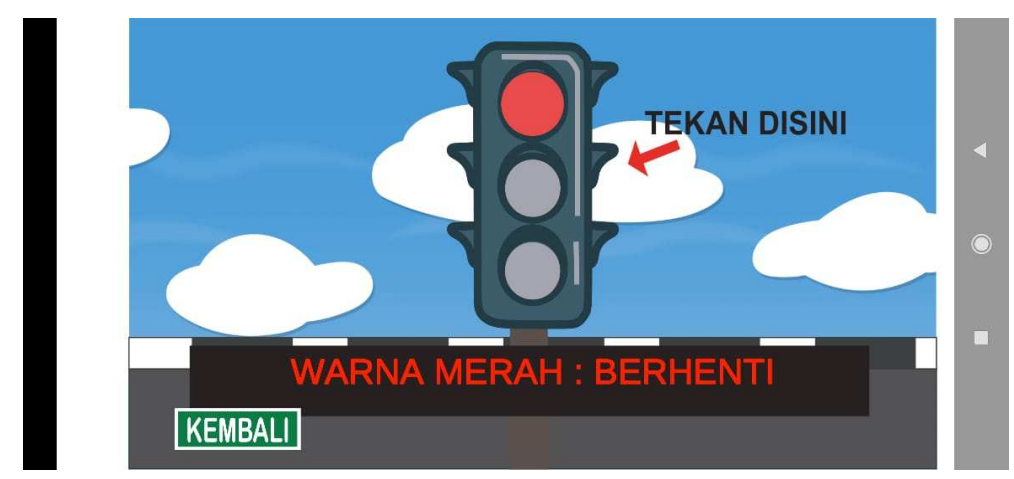

(c) Multimedia interaktif materi APILL 


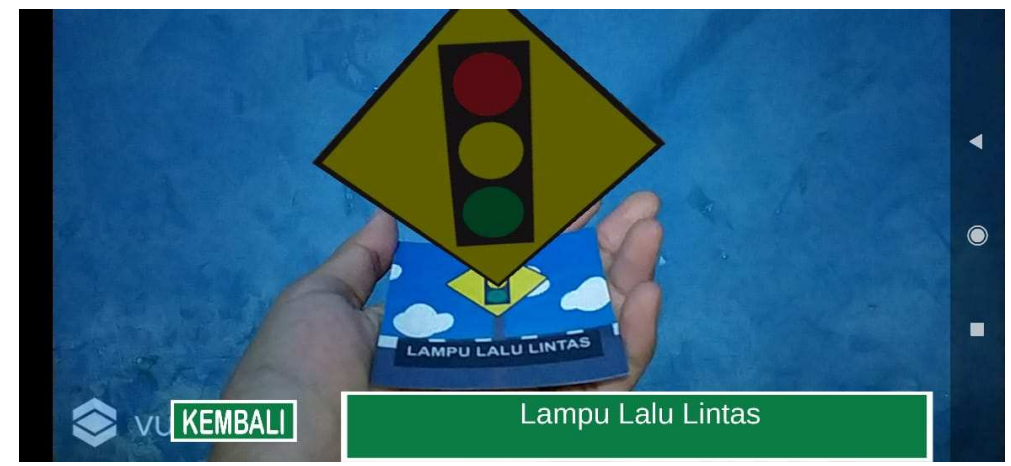

(c) Penggunaan AR untuk materi rambu-rambu lalu lintas

Gambar 4. Gambaran aplikasi pengenalan rambu lalu lintas dan APILL berbasis mobile

\section{Pelatihan mitra}

Pelatihan dilakukan ke semua guru di TK Kemala Bhayangkari No 72 Wonogiri dalam penggunaan aplikasi pengenalan rambu lalu lintas dan APILL berbasis mobile. Bentuk pelatihan terdiri dari cara memakan alat peraga rambu lalu lintas dan APILL, instalasi aplikasi pengenalan rambu lalu lintas dan APILL berbasis mobile di smartphone masing-masing guru dan langkah pengoperasian aplikasi pengenalan rambu lalu lintas dan APILL berbasis mobile. Kendala yang dihadapi dalam pelatihan ini yakni pada instalasi aplikasi. Hal ini disebabkan karena ketersediaan free storage smartphone, sehingga harus membantu guru terlebih dahulu menghapus files yang sudah tidak dipakai. Kegiatan pelatihan ini dimulai jam 10.30 setelah siswa pulang sampai dengan jam 13.00 bertempat di ruang kelas TK Kemala Bhayangkari No 72 Wonogiri seperti ditunjukkan pada Gambar 5. Pembelajaran dengan memanfaatkan sifat mobile device dapat membuat pembelajaran menarik dan interaktif.

\section{Pendampingan mitra}

Pendampingan mitra dimaksudkan mendampingi guru TK Kemala Bhayangkari No 72 Wonogiri dalam menerapkan aplikasi pengenalan rambu lalu lintas dan APILL berbasis mobile di pembelajaran. Proses pendampingan dilakukan dengan cara tim pelaksana pengabdian kepada masyarakat mendampingi guru, ketika menggunakan aplikasi augmented reality dalam pembelajaran di kelas. Hal ini dimaksudkan, bilamana terjadi kendala teknis dalam pengoperasian aplikasi, tim pelaksana dapat membantu secara langsung. Kegiatan pembelajaran ini menjadi interaktif karena siswa dapat berinteraksi langsung dengan alat peraga untuk memeragakan sesuai dengan fungsi rambu lalu lintas dan APILL. Tidak hanya itu, melalui aplikasi pengenalan rambu lalu lintas dan APILL berbasis digital siswa dapat mengikuti gerakan profesi polisi dalam mengatur lalu lintas sesuai dengan animasi yang ditampilkan didalam aplikasi. Kondisi ini membuat siswa sangat senang dan sangat aktif dalam mengikuti pembelajaran sebagaimana ditampilkan pada Gambar 6. 


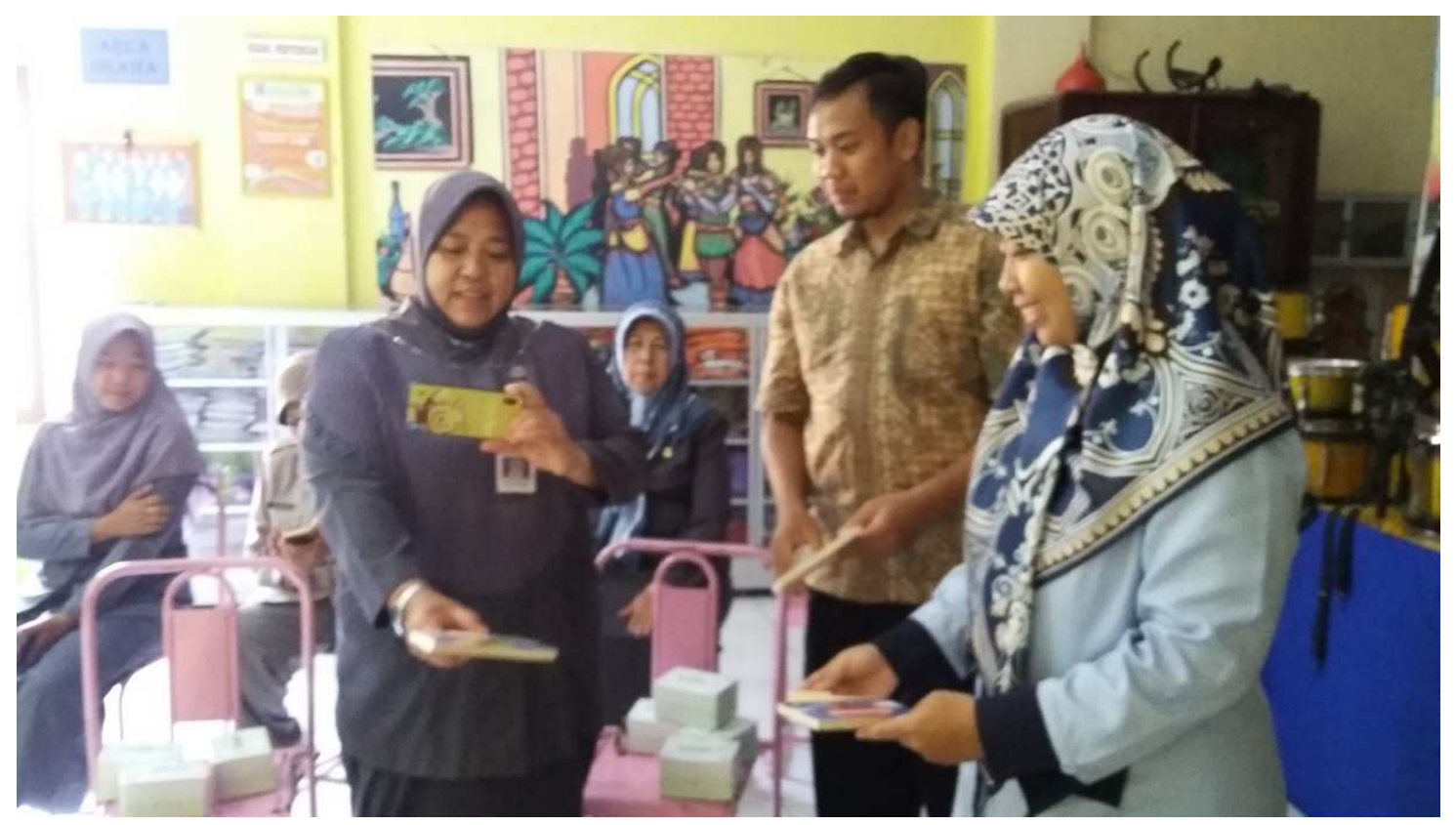

Gambar 5. Pelatihan guru dalam penggunaan alat peraga dan aplikasi

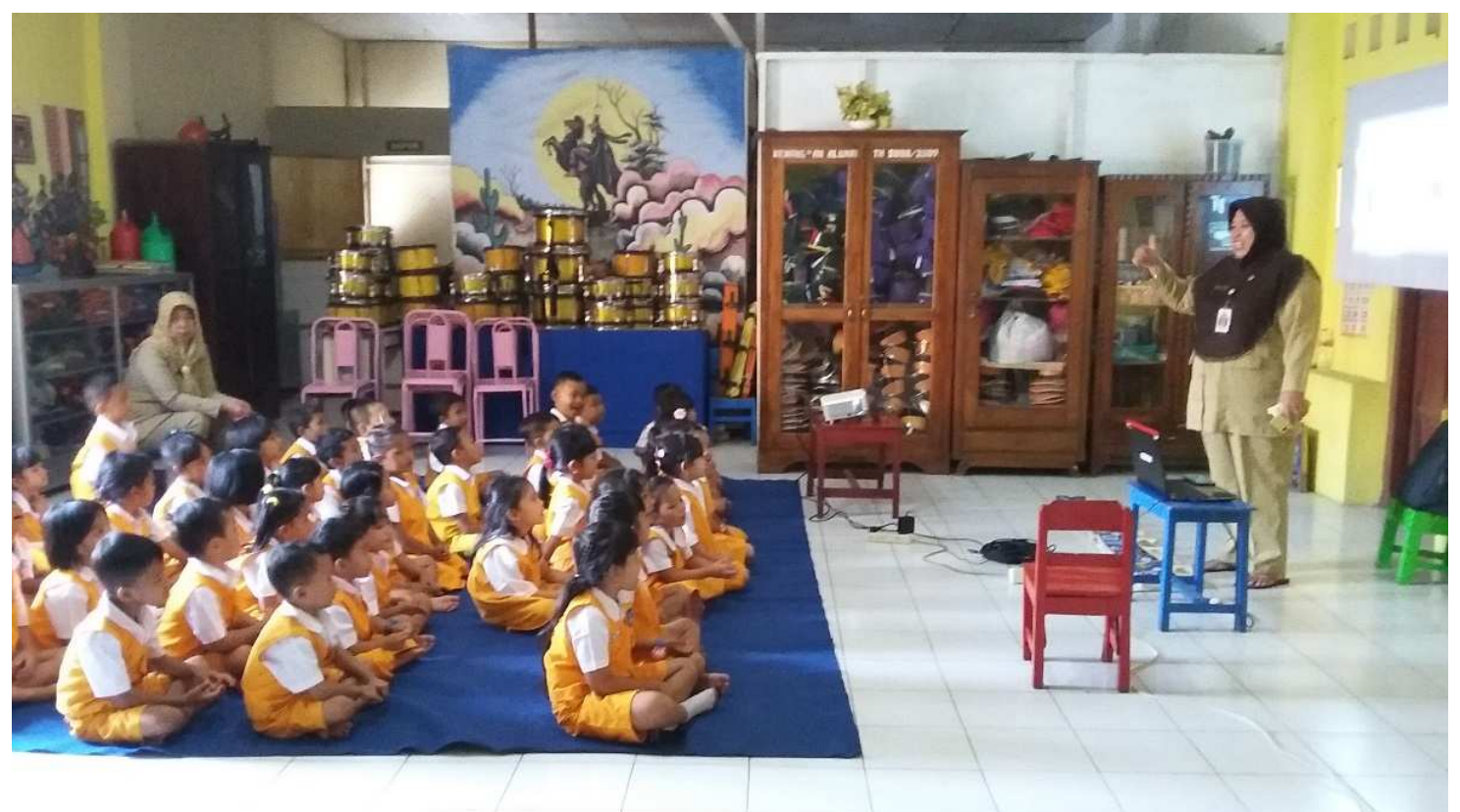

Gambar 6. Penerapan alat peraga dan aplikasi dalam kegiatan pembelajaran

\section{KESIMPULAN}

Kesimpulan yang diperoleh dari kegiatan pengabdian ini meliputi penerapan teknologi tepat guna media pembelajaran digital berupa aplikasi AR sebagai media pembelajaran digital, peningkatan kompetensi guru TK Kemala Bhayangkari No 72 Wonogiri dalam penggunaan media digital di pembelajaran dan penyediaan sarana prasarana belajar di TK Kemala Bhayangkari No 72 Wonogiri berupa alat peraga dan aplikasi digital pengenalan rambu lalu lintas dan APILL. Aplikasi digital tersebut dapat dijalankan melalui smartphone masing-masing guru selama proses melaksanakan pembelajaran di kelas. Pembelajaran yang memanfaatkan 
sifat mobile ini lebih menarik dan interaktif (Putra, dkk, 2016). Selanjutnya, kegiatan pengabdian kepada masyarakat dapat dilakukan dengan mengembangkan aplikasi pembelajaran dengan submateri lainnya

\section{UCAPAN TERIMA KASIH}

Kegiatan pengabdian masyarakat ini dilakukan melalui pendanaan internal Universitas Duta Bangsa Surakarta tahun 2019.

\section{DAFTAR PUSTAKA}

Danaei, D., Jamali, H. R., Mansourian, Y., \& Rastegarpour, H. (2020). Comparing reading comprehension between children reading augmented reality and print storybooks. Computers and Education, 153(March), 103900. https://doi.org/10.1016/j.compedu.2020.103900

Delfita, R. (2012). Meningkatkan kemampuan berbahasa anak melalui permainan gambar dalam bak pasir di Taman Kanak-Kanak Bina Anaprasa Mekar Sari Padang. JURNAL ILMIAH PESONA PAUD, $I(1), 1-10$.

Gusnita, E., Hartati, S., \& Marlina, S. (2019). Peningkatan kemampuan mengenal huruf anak usia dini melalui alphabet book di Taman Kanak-Kanak. Journal of Family, Adult and Early Childhood Education, 1(1), 87-92. https://doi.org/10.5281/zenodo.2571329

Hanafri, M. I., Ramdhan, S., \& Nisa, K. (2017). Aplikasi pembelajaran interaktif pengenalan profesi berbasis multimedia menggunakan Adobe Flash CS6. Jurnal Sisfotek Global, 7(2), 38-44.

Handayani, S. (2018). Development of interactive multimedia learning media to improve counting ability group students A TK Dharma Wanita Batursari. Journal of Curriculum Indonesia, 1(2), 55-60.

Lee, L. K., Chau, C. H., Chau, C. H., Ng, C. T., Hu, J. H., Wong, C. Y., \& Yu, L. C. (2019). Improving the experience of teaching and learning kindergarten-level English vocabulary using augmented reality. International Journal of Innovation and Learning, 25(2), 110-125. https://doi.org/10.1504/ijil.2019.10018266

Nurchim, N., \& Nofikasari, I. (2018). Analisis model pengembangan telecenter guna mewujudkan Desa Pintar di Indonesia. Fountain of Informatics Journal, 3(2), 36-40.

Oranç, C., \& Küntay, A. C. (2019). Learning from the real and the virtual worlds: Educational use of augmented reality in early childhood. International Journal of Child-Computer Interaction, 21, 104-111. https://doi.org/10.1016/j.ijcci.2019.06.002

Putra, A. G., Hasanah, H., \& Atina, V. (2016). Aplikasi mobile learn english memanfaatkan speech recognition pada Google Voice. Jurnal IT CIDA, 2(2), 36-46.

Roza, M. M. (2012). Pelaksanaan pembelajaran sains anak Taman Kanak-Kanak Aisyiyah Bustanul Athfal 29 Padang. Jurnal Ilmiah Pesona PAUD, 1(17), 1-11.

Wahyuni, W., Permatasari, H., \& Utomo, B. P. C. (2020). Custom world dengan fitur augmented reality (Studi kasus: Toko Kingkong Custom World). Jurnal Sainstech Politeknik Indonusa Surakarta, 7(1), 43-51.

Yilmaz, R. M. (2016). Educational magic toys developed with augmented reality technology for early childhood education. Computers in Human Behavior, 54, 240-248. https://doi.org/10.1016/j.chb.2015.07.040 